\title{
Effects of desipramine on the cell cycle and apoptosis in Ca3/7 mouse skin squamous carcinoma cells
}

\author{
TATSUYA KINJO ${ }^{2}$, PIOTR KOWALCZYK ${ }^{1}$, MAGDALENA KOWALCZYK ${ }^{1}$, \\ ZBIGNIEW WALASZEK ${ }^{1}$, THOMAS J. SLAGA ${ }^{1}$ and MARGARET HANAUSEK ${ }^{1}$ \\ ${ }^{1}$ Department of Pharmacology, University of Texas Health Science Center at San Antonio, San Antonio, \\ 7703 Floyd Curl Drive, San Antonio, TX 78229, USA; ${ }^{2}$ Division of Digestive and General Surgery, \\ University of the Ryukyus Faculty of Medicine, 207 Uehara Nishihara-cho, Okinawa 903-0215, Japan
}

Received March 9, 2010; Accepted April 12, 2010

DOI: $10.3892 /$ ijmm_00000415

\begin{abstract}
Desipramine (DMI) has been reported to induce glucocorticoid receptor-mediated signal transduction in recent studies. It has been suggested that a non-glucocorticoid receptor signaling pathway might play an important role in skin squamous carcinoma Ca3/7 cells. The aim of this study was to investigate the growth inhibitory effects of DMI on Ca3/7 cells by evaluating the mRNA expression of genes related to apoptosis and cell cycle progression. Hoechst nuclear staining and DNA fragmentation assays were used to detect apoptosis, and the cell cycle was analyzed by flow cytometry. Apoptotic bodies in the nuclei of cells and DNA fragmentation were observed when the Ca3/7 cells were treated with $20 \mu \mathrm{M}$ DMI for $24 \mathrm{~h}$. Quantitative RT-PCR (reverse transcriptional-polymerase chain reaction) showed that DMI caused a decrease in Bcl-2 and survivin but not $\mathrm{Bcl}-\mathrm{xL}$ gene expression and an increase in the expression of Bax, Apaf-1, caspase- 3 and caspase- 7 in a dose- and timedependent manner. DMI also caused translocation of the apoptosis-inducing factor from the cytoplasm to the nucleus as well as cell cycle arrest in the Ca3/7 cells. Quantitative RT-PCR revealed that DMI decreased the expression of the PCNA gene and caused an increase in the expression of the p21 and p27 genes in the Ca3/7 cells. Our results showed that DMI inhibited the growth of $\mathrm{Ca} 3 / 7$ cells by inducing both apoptosis and cell cycle arrest.
\end{abstract}

\section{Introduction}

The tricyclic antidepressant desipramine (DMI) inhibits the uptake of norepinephrine and is used primarily for the

Correspondence to: Dr Margaret Hanausek, Department of Pharmacology, University of Texas Health Science Center at San Antonio, 7703 Floyd Curl Drive, San Antonio, TX 78229, USA

E-mail: hanausek@uthscsa.edu

Key words: SENCAR mice, apoptosis, cell cycle arrest, desipramine treatment of depression. Recent studies have demonstrated that antidepressants decrease the risk of breast cancer development (1-4). On the other hand, several studies have reported that antidepressants increase the risk of nonHodgkin lymphoma and prostate cancer $(5,6)$, and it is still controversial what effect tricyclic antidepressants have on lung, breast and colon cancer cells (7-9). Both in vitro and in vivo studies indicate antidepressants are cytotoxic to most malignant cells, particularly colon and breast cancer (10-12). The induction of apoptosis by DMI has been demonstrated to be significant in colon cancer, glioma and renal tubular cells (13-19). In these studies, an increase in intracellular calcium and caspase-3 appear to play a pivotal role in the induction of DNA fragmentation. The relationship between DMI and cancer cell survival is still equivocal and not fully understood. DMI is thought to exert its effects on glucocorticoid receptor (GR) function by modulating membrane steroid transporters and to exert an inhibitory effect on cell growth (20-22). Antidepressants induce translocation of GR from the cytoplasm into the nucleus (23). Moreover, DMI was found to induce an increase in GR-mediated transcription in a mouse fibroblast cell line (22). A chief action of DMI on growth inhibition might directly modulate GR by facilitating GR translocation to the nucleus.

Our previous study found that both the papilloma cell line MT1/2 and the squamous cell carcinoma cell line Ca3/7, but not the non-tumorigenic cell line 3PC, were resistant to growth inhibition by glucocorticoids (24). It was shown that MT1/2 and $\mathrm{Ca} 3 / 7$ cells were resistant to glucocorticoids due to an alteration of GR function, but not due to a reduction in GR expression or gene mutation. In our previous study (25), the ATP-bioluminescence assay was used to estimate the cell viability of the three murine keratinocyte cell lines, nontumorigenic 3PC, papilloma-derived MT1/2 and squamous cell carcinoma-derived Ca3/7, treated with DMI. We hypothesized that DMI causes a growth inhibitory effect, particularly on Ca3/7 cells by inducing GR translocation from the cytoplasm to the nucleus. However, we found that DMI caused a decrease in the cell viability in 3PC, MT1/2 and $\mathrm{Ca} 3 / 7$ cells, but this was not due to any significant effect on GR-mediated signal transduction. It was also suggested that a non-glucocorticoid receptor signaling pathway might play a 
Table I. Primer sequences used for genes expression quantification.

\begin{tabular}{lll}
\hline Gene & \multicolumn{1}{c}{ Forward primer (5'-3') } & \multicolumn{1}{c}{ Reverse primer (5'-3') } \\
\hline B-actin & CATCCTGGCCTCGCTGTC & CTCGTCGTACTCCTGCTTGGT \\
p21 & CTCAGACACCAGAGTGC & GACAGTGAGCAGTTGCG \\
p27 & TCAAACGTGAGAGTGTCTAACGG & AGGGGCTTATGATTCTGAAAGTCG \\
PCNA & GATGTGGAGCAACTTGGAAT & AGCTCTCCACTTGCAGAAAA \\
Bcl-2 & CTCGTCGCTACCGTCGTGACTTCG & CAGATGCCGGTTCAGGTACTCAGTC \\
Bcl-xL & TGGAGTAAACTGGGGGTCGCATCG & AGCCACCGTCATGCCCGTCAGG \\
Bax & TGAAGACAGGGGCCTTTTTG & AATTCGCCGGAGACACTCG \\
Apaf-1 & AGTAATGGGTCCTAAGCATGTTG & GCGATTGGGAAAATCACGTAAAA \\
Survivin & ATCCACTGCCCTACCGAGAA & CTTGGCTCTCTGTCTGTCCAGTT \\
Caspase-3 & TCTGACTGGAAAGCCGAAACT & AGGGACTGGATGAACCACGAC \\
Caspase-7 & CTGAGGAGGACCACAGCAACT & ACCGTGGAGTAAGCAAAGAGG \\
\hline
\end{tabular}

more important role in the growth inhibition by DMI. It is presently not known why apoptosis and/or arrest of cell cycle progression are associated with the growth inhibitory effects of DMI. Therefore in the present study, we studied the effect of DMI on apoptosis and arrest of cell cycle progression in Ca3/7 cells using DNA fragmentation and apoptotic body analyses and flow cytometry, respectively.

\section{Materials and methods}

Chemicals and cell culture. The $\mathrm{Ca} 3 / 7$ cell line was obtained from squamous cell carcinomas induced in SENCAR mice by the standard two-stage DMBA/TPA protocol as previously described (25). Ca3/7 cells were cultured in Eagle's minimal essential medium with $0.05 \mathrm{mM}$ of $\mathrm{Ca}^{2+}$ supplemented with $4 \%$ charcoal-extracted, heat-inactivated fetal bovine serum, insulin $(5 \mu \mathrm{g} / \mathrm{ml})$, epidermal growth factor $(5 \mathrm{ng} / \mathrm{ml})$, transferrin $(10 \mu \mathrm{g} / \mathrm{ml})$ O-phosphoethanolamine $(10 \mu \mathrm{M})$, ethanolamine $(10 \mu \mathrm{M})$, glutamine $(2 \mu \mathrm{M})$, penicillin $(50 \mathrm{U} / \mathrm{ml})$ and streptomycin $(50 \mathrm{ng} / \mathrm{ml})$. Cells were treated with DMI purchased from Sigma Aldrich Co. (St. Louis, MO) and cultured in an incubator with humidified air with $5 \% \mathrm{CO}_{2}$ at $37^{\circ} \mathrm{C}$. As an untreated solvent control, cells were treated with ethanol at a final concentration $<0.1 \%$.

Immunocytochemistry. A key mediator of apoptosis, mitochondrial function and cell survival is the apoptosisinducing factor AIF. In the present study, we investigated the effect of DMI on AIF translocation in murine skin cancer cells using an anti-AIF antibody. To improve AIF antibody penetration, cells were permeabilized with $0.2 \%$ Triton X-100 before exposure to the anti-AIF antibody (Santa Cruz Biotechnology, Santa Cruz, CA). Slides were incubated with the anti-AIF antibody and treated with Cy2-conjugated secondary antibody (Jackson ImmunoResearch, West Grove, PA). The cells were mounted with DAPI containing anti-fade mounting medium (Vectashield; Vector Laboratories, Inc., Burlingame, CA) and viewed with an epi-fluorescence microscope (Olympus Optical Co., Ltd., Melville, NY). For negative controls, the slides were incubated with $10 \%$ normal goat serum containing $0.6 \%$ Triton X-100 instead of the primary antibody showing a lack of specific immunoreactivity. To examine the relation between the growth inhibition of $\mathrm{Ca} 3 / 7$ cells and the induction of apoptosis, we carried out Hoechst staining in addition to DNA fragmentation analysis (described below). Apoptotic bodies were observed in the nuclei of the cells treated with 10 and $20 \mu \mathrm{M}$ of DMI for $24 \mathrm{~h}$. For a fluorescence cytochemical study, the cells were plated on poly-D-lysine-coated wells at a density of $2 \times 10^{5}$ cells/well and exposed to DMI for $24 \mathrm{~h}$. The cells were rinsed with $\mathrm{PBS}$ and fixed with methanol for $40 \mathrm{~min}$ followed by $75 \%$ ethanol for $1 \mathrm{~h}$ at room temperature. The fixed cells were stained with propidium iodide (Sigma Aldrich) in PBS for $10 \mathrm{~min}$ at room temperature and examined using a fluorescence microscope.

DNA fragmentation analysis. For DNA fragmentation analysis, the cells were plated on a $10-\mathrm{mm}$ culture dish at a density of $2 \times 10^{6}$ cells/dish and exposed to different concentrations of DMI for $24 \mathrm{~h}$. The cells which attached to the bottom of the dish were scraped off and collected together with unattached cells by centrifuging at $800 \mathrm{x}$ g for 5 min at $4^{\circ} \mathrm{C}$. The DNA was prepared from the pelleted cells and applied to a $2 \%$ agarose gel containing $0.5 \mathrm{mg} / \mathrm{ml}$ of ethidium bromide for electrophoretic analysis.

Flow cytometry. Cells were plated on a $10-\mathrm{mm}$ culture dish at a density of $1 \times 10^{6}$ cells/dish and maintained for $24 \mathrm{~h}$. After exposing the cells to DMI for the next $24 \mathrm{~h}$, the cells were harvested by trypsinization, rinsed with PBS, and then fixed with $70 \%$ ethanol for $10 \mathrm{~min}$. The fixed cells were incubated with propidium iodide $(10 \mu \mathrm{g} / \mathrm{ml})$ and RNase A $(10 \mu \mathrm{g} / \mathrm{ml})$ in PBS at room temperature for $30 \mathrm{~min}$ in the dark, and the DNA contents of the cells were analyzed using flow cytometry.

RNA extraction and cDNA synthesis. Total RNA was extracted from Ca3/7 cells treated with DMI using Trizol reagent (Invitrogen, Carlsbad, CA) following DNase 1 (Sigma Aldrich) treatment and reverse-transcribed with the 
A

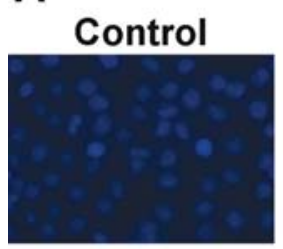
$10 \mu \mathrm{M}$ DMI
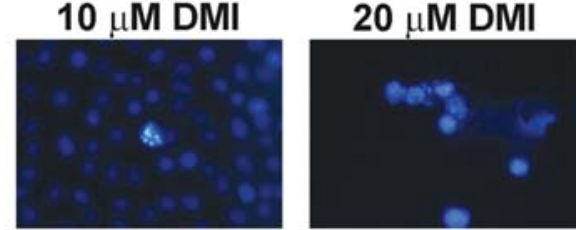

B

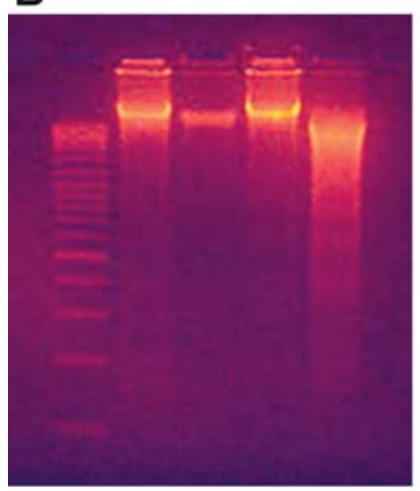

C
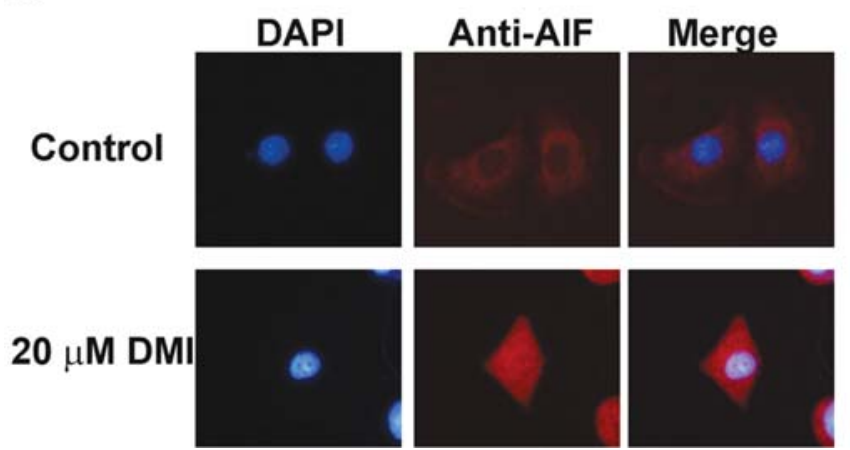

Figure 1. Induction of apoptosis by DMI in mouse squamous carcinoma Ca3/7 cells. (A) Hoechst staining was carried out after exposing Ca3/7 cells to 10 and $20 \mu \mathrm{M}$ DMI for $24 \mathrm{~h}$. (B) DNA fragmentation was noted after exposing cells to $20 \mu \mathrm{M}$ of DMI for $24 \mathrm{~h}$. (C) Translocation of AIF after treatment with DMI. Ca3/7 cells were treated with vehicle or $20 \mu \mathrm{M}$ DMI for $24 \mathrm{~h}$. AIF was visualized by immunostaining using the anti-AIF monoclonal antibody. Images of the DAPI and AIF fluorescence patterns were merged to visualize the nuclear localization.

Masterscript $^{\mathrm{TM}}$ Kit (5Prime, Inc., Gaithersburg, MD) using an oligo-dT primer. RNA isolated from vehicle-treated Ca3/7 cells served as controls.

Quantitative RT-PCR. Specific primers for apoptosis- and cell cycle arrest-related genes were used for real-time PCR as shown in Table I. Standard quantitative RT-PCR was performed in triplicate using SYBR Green RealMaster Mix (Eppendorf North America, Westbury, NY) on the Realplex MasterCycler (Eppendorf). RT-PCR cycle thresholds $(\mathrm{Ct})$ of the candidate genes were normalized to $B$-actin. The formula $2 \mathrm{Ct}$ (candidate)/2Ct (control) was used to calculate the normalized ratios.

Statistical analysis. Data are presented as the mean \pm standard deviation (SD). For comparison of the differences between the groups, ANOVA analysis followed by the Dunnett's test was used. Differences were considered statistically significant at a $\mathrm{P}$-value $<0.05$.

\section{Results}

DMI induces apoptosis in Ca3/7 cells. DMI has been shown to induce apoptosis in several cancer cell lines (13-19). In our previous study, we also examined the effect of DMI on the growth of three murine skin cell lines (3PC, MT1/2 and Ca3/7) representing different stages of skin carcinogenesis. All of the cell lines were treated with various concentrations of DMI for $12,24,48,72$, and $96 \mathrm{~h}$ which resulted in the suppression of cell growth in a dose- and time-dependent manner (25). In the present study we focused on the carcinomaproducing cell line Ca3/7 treated with 1,10 or $20 \mu \mathrm{M}$ DMI. After a 24-h incubation with the chosen DMI concentrations we noted almost no effect at $1 \mu \mathrm{M}$, cell viability $\sim 80 \%$ at $10 \mu \mathrm{M}$ and $40 \%$ cell viability at $20 \mu \mathrm{M}$. To examine the relation between DMI growth inhibition of $\mathrm{Ca} 3 / 7$ cells and induction of apoptosis, we carried out Hoechst staining and DNA fragmentation analysis. Apoptotic bodies were observed in the nuclei of the cells treated with $20 \mu \mathrm{M}$ DMI for $24 \mathrm{~h}$ (Fig. 1A). DNA fragmentation was also observed after exposing the cells to various concentrations of DMI for $24 \mathrm{~h}$ (Fig. 1B). These results revealed that DMI obviously caused apoptotic damage to $\mathrm{Ca} 3 / 7$ cells, resulting in a decrease in cell viability as previously described (25).

DMI causes an increase in pro-apoptotic and a decrease in anti-apoptotic gene expression. We evaluated the expression of anti-apoptotic and pro-apoptotic genes in $\mathrm{Ca} 3 / 7$ cells at 24, 48, and $72 \mathrm{~h}$ after treatment with different concentrations of DMI using quantitative RT-PCR. DMI induced a reduction in Bcl-2 in a dose-dependent manner following a 24-, 48- and 72-h incubation except for a 72-h incubation with $20 \mu \mathrm{M}$ DMI (Fig. 2A). Survivin gene expression was also reduced by DMI in a dose-dependent manner after $72 \mathrm{~h}$, and a decrease in mRNA level was also observed in cells treated with $20 \mu \mathrm{M}$ DMI after 24 and 48 h (Fig. 2C). In addition, DMI obviously increased the expression of the Bcl-xL gene in a dose- and time-dependent manner (Fig. 2B). In contrast, regarding genes related to the induction of apoptosis, DMI caused an increase in the expression of Bax (Fig. 2D), Apaf-1 (Fig. 2E), caspase-3 (Fig. 2F) and caspase-7 (Fig. 2G) in a dose- and timedependent manner.

DMI induces the translocation of AIF from the cytoplasm to the nucleus in Ca3/7 cells. To assess the induction of apoptosis by DMI, we examined the translocation of AIF in Ca3/7 cells treated with DMI. To evaluate the effect of DMI on the translocation of AIF, we used an immunofluorescence staining procedure with an anti-AIF monoclonal antibody (Fig. 1C). $\mathrm{Ca} 3 / 7$ cells were treated with vehicle or $20 \mu \mathrm{M}$ DMI for $24 \mathrm{~h}$ and then stained for the AIF. After treatment with DMI, the pattern of staining was diffuse in both the cytoplasm and the nucleus. DMI is suggested to induce apoptosis in $\mathrm{Ca} 3 / 7$ cells by the induction of both caspases and AIF. It seems conceivable that the induction of apoptosis in the Ca3/7 cells treated with DMI was associated with a reduction in the expression of the Bcl-2 gene.

DMI causes cell cycle arrest in Ca3/7 cells. To further characterize the effect of DMI on the growth inhibition of 


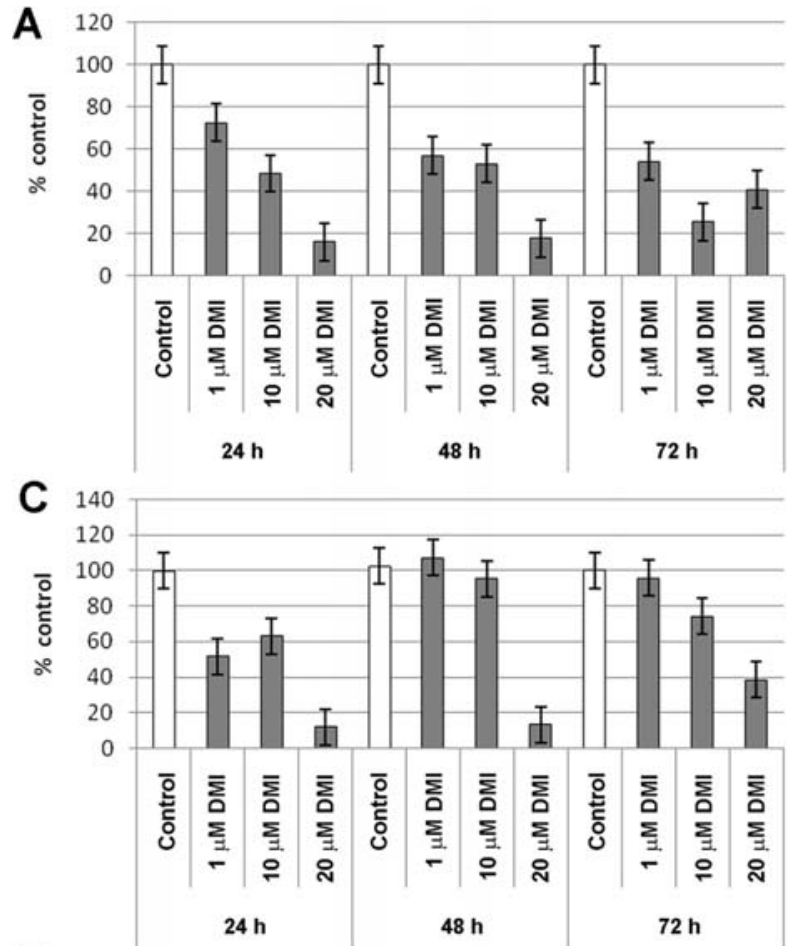

E
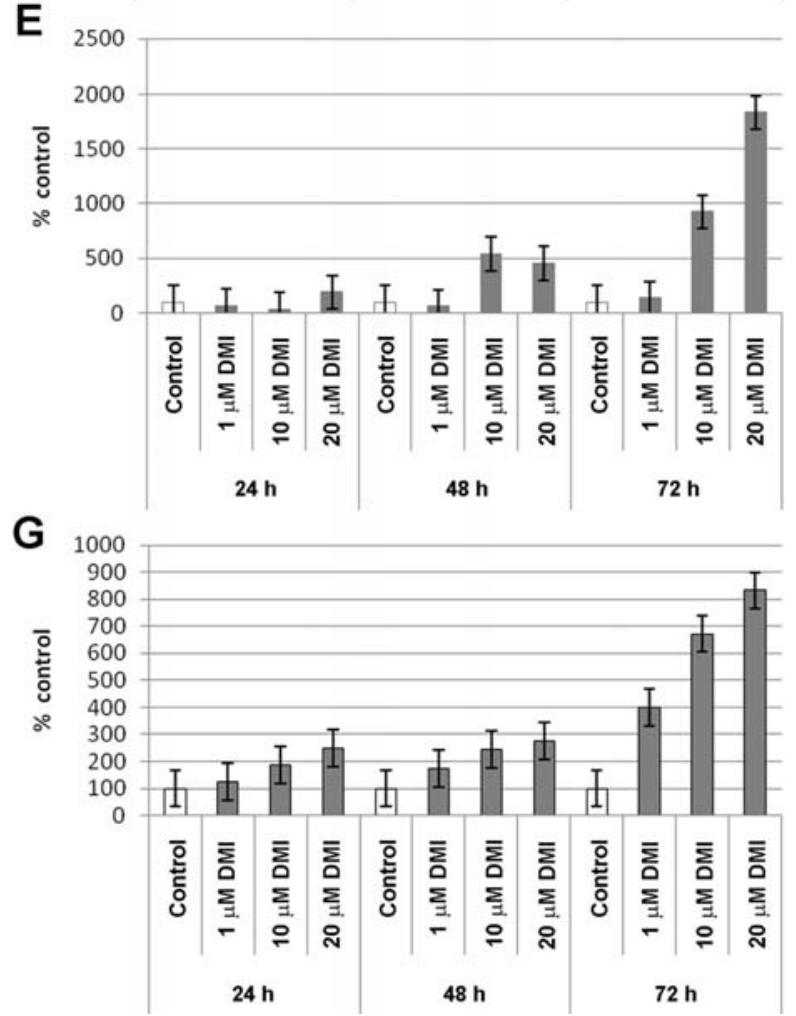

mouse skin carcinoma cells, $\mathrm{Ca} 3 / 7$ cells were exposed to different concentrations of DMI and then subjected to flowcytometric analysis of the cell cycle. As shown in Fig. 3, a low concentration of DMI $(1 \mu \mathrm{M})$ increased the number of cells in the G0/G1 phase with a concomitant decrease in cells in the $\mathrm{S}$ phase, while a high concentration of the drug $(20 \mu \mathrm{M})$ significantly decreased the number of G0/G1-phase cells with a marked increase in the number of cells in the G2/M phase. A moderate concentration of DMI $(10 \mu \mathrm{M})$ increased the cell numbers in the G0/G1 and G2/M phases with a significant decrease in the number of cells in the $S$ phase.
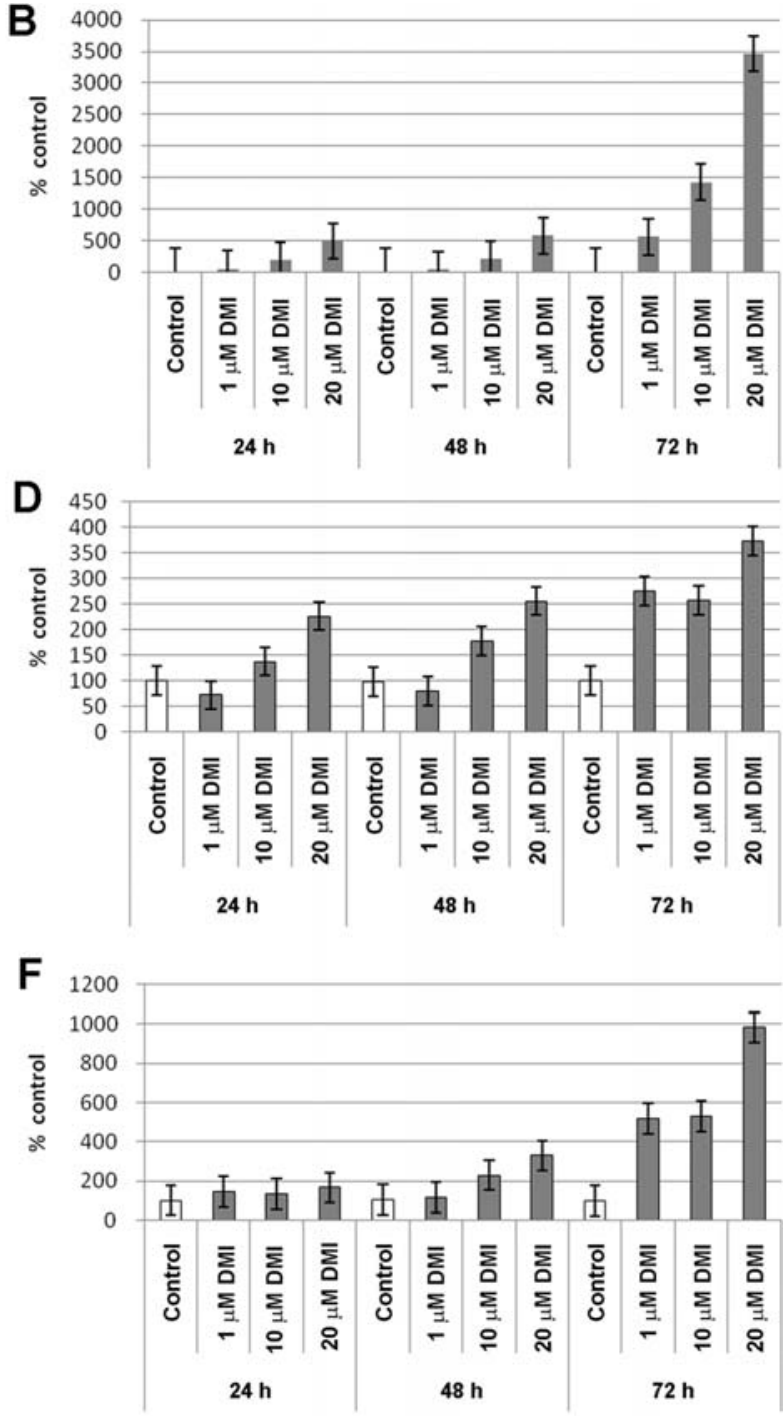

Figure 2. Expression of anti-apoptotic and pro-apoptotic genes in $\mathrm{Ca} 3 / 7$ cells after treatment with DMI. The gene expression was analyzed at 24,48 , and $72 \mathrm{~h}$ after treatment with 10 and $20 \mu \mathrm{M}$ of DMI by quantitative RTPCR. Expression levels were normalized against $\beta$-actin and were represented as the percentage of the vehicle-treated control. The following genes were analyzed for DMI reduction of expression: Bcl-2 (A), Bcl-xL (B) and survivin (C). Genes related to apoptosis induction by DMI: Bax (D), Apaf-1 (E), caspase-3 (F) and caspase-7 (G) were also analyzed. Results are shown as the mean \pm SD from triplicate assays. A significant difference $(\mathrm{P}<0.05)$ was measured using ANOVA followed by the Dunnett's test.

Thus, exposure of Ca3/7 cells to DMI caused apoptotic cell death, which might be largely attributed to the arrest of cell cycle progression (Fig. 3).

DMI increases the expression of genes involved in the arrest of cell cycle progression. Cell cycle-related gene expression in Ca3/7 cells was analyzed at 24, 48 and $72 \mathrm{~h}$ after treatment with 1,10 and $20 \mu \mathrm{M}$ of DMI using quantitative RT-PCR. DMI decreased the expression of PCNA (Fig. 4A) and concomitantly increased the expression of the p21 (Fig. 4B) and p27 (Fig. 4C) genes. These results suggest that DMI- 


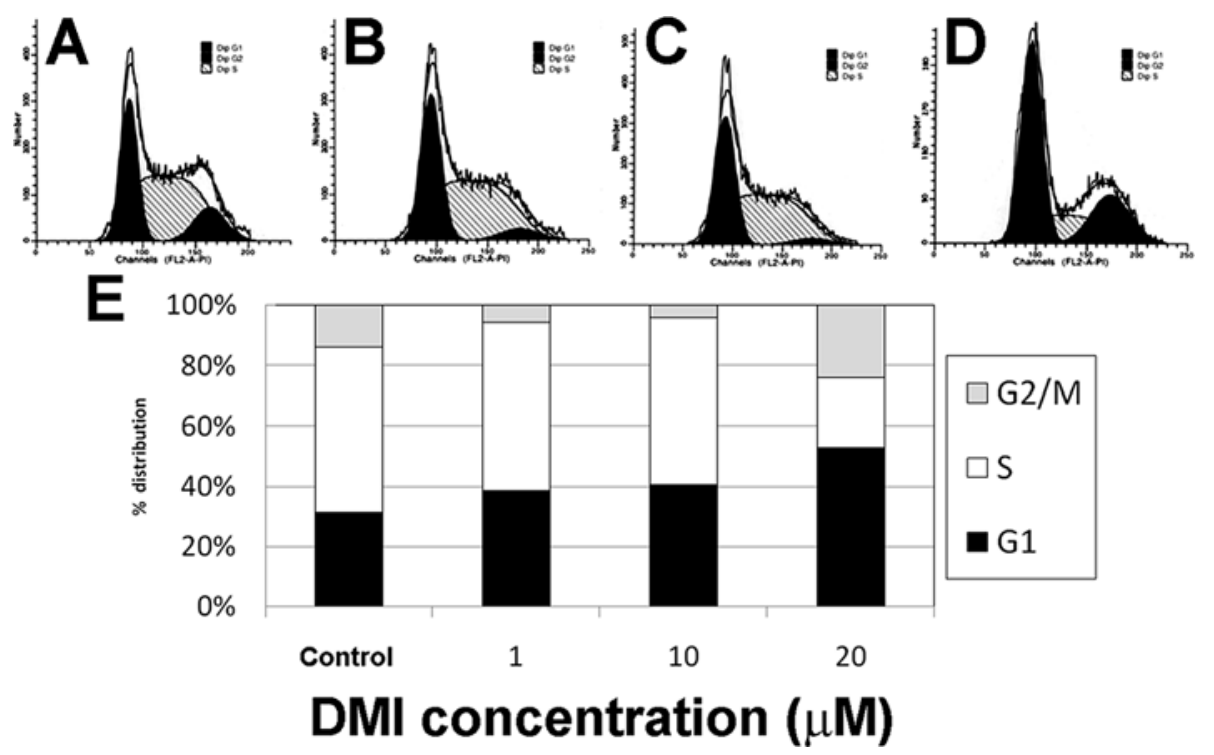

Figure 3. Flow cytometric analysis of the cell cycle distribution of Ca3/7 cells treated with DMI. Ca3/7 cells were exposed to 1,10 and $20 \mu \mathrm{M}$ DMI for $24 \mathrm{~h}$, and the cell cycle distribution was analyzed. The proportion of cells in the G1 phase increased in a dose-dependent manner after exposure to DMI from 0 to $10 \mu \mathrm{M}$ (A, B and C, respectively), while $20 \mu \mathrm{M}$ DMI increased the proportion of cells in the G1 phase with a marked increase in cells in the G2/M phase and a concomitant decrease in cells in the $\mathrm{S}$ phase (D). The percent distribution is shown in $\mathrm{E}$.

A

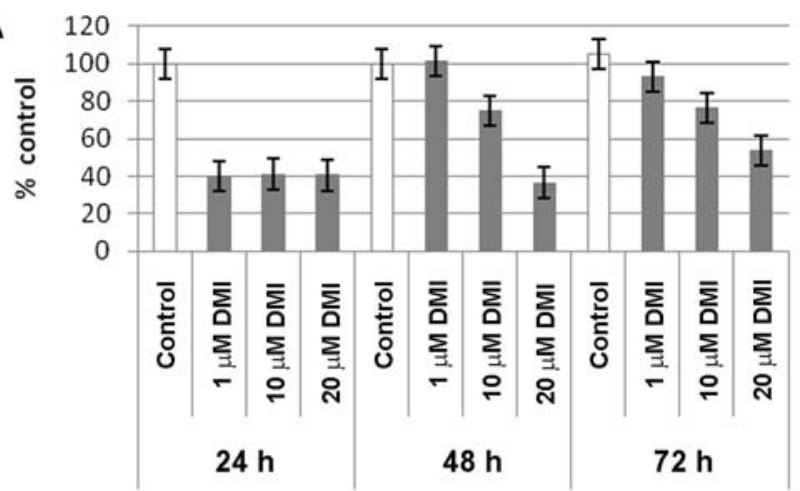

C

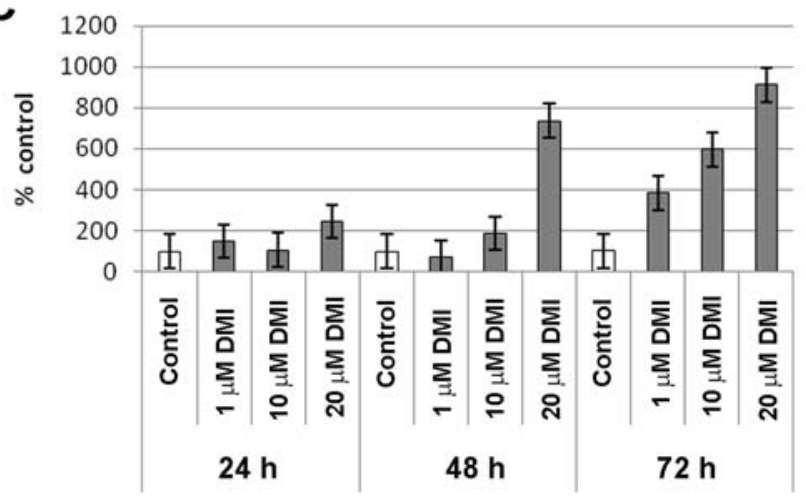

induced apoptotic cell death is largely associated with the arrest of cell cycle progression.

\section{Discussion}

The present study demonstrated that DMI induces growth inhibition through the induction of apoptosis and arrest of cell cycle progression in mouse skin squamous cell carcinoma cells. These findings are in agreement with previous studies which found that DMI inhibited cell proliferation and

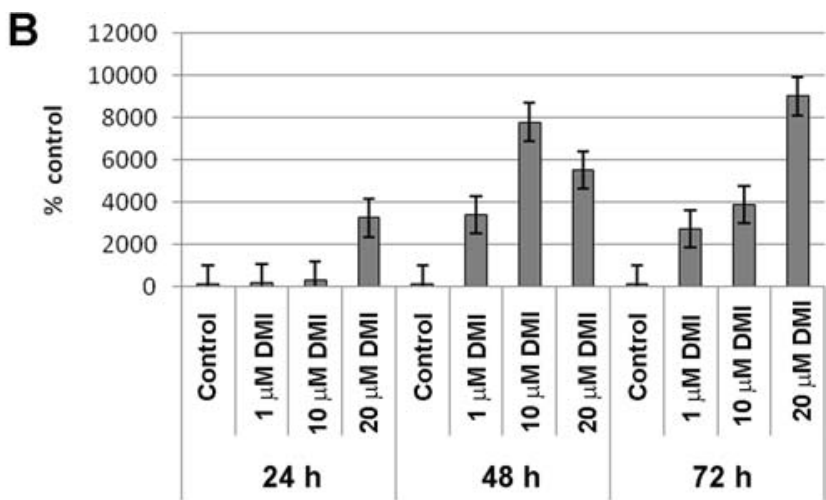

Figure 4. Expression of cell cycle-related genes in Ca3/7 cells after treatment with DMI. Gene expression of cell cycle-related genes in Ca3/7 cells was analyzed at 24,48 and $72 \mathrm{~h}$ after treatment with 1,10 and $20 \mu \mathrm{M}$ of DMI by quantitative RT-PCR. Expression levels were normalized against $\beta$-actin and were represented as the percentage of the vehicle-treated control. DMI induced a reduction in the expression of the PCNA gene (A) while increasing the expression of the p21 (B) and p27 (C) genes. Results are shown as the mean \pm SD from triplicate assays. A significant difference $(\mathrm{P}<0.05)$ was measured using ANOVA followed by the Dunnett's test.

induced apoptosis in osteosarcoma cells, prostate cancer, colon cancer, renal tubular and glioma cells $(14,15,26-29)$ and caused cell cycle arrest in colon cancer cells (13). In this study, we found a decrease in mRNA expression of Bcl-2 and survivin. We also found that mRNA expression of caspase-3 and -7 was increased after DMI treatment in a time- and dosedependent manner. The involvement of caspase-3 was also demonstrated by Qi et al (14). It is conceivable that DMI induces apoptosis via the mitochondrial pathway, which causes release of cytochrome $\mathrm{c}$ from the mitochondria to the 
cytoplasm which subsequently activates caspases to induce DNA fragmentation. A previous study found that DMI may cause non-oxidative apoptotic damage to different types of carcinoma cells through either a non-mitochondrial or a mitochondrial pathway, which may be related to different sensitivities of these cancer cells to this drug $(13,28)$. Moreover, DMI caused arrest of cell cycle progression in either the G0/G1 or G2/M phase, which might be dependent upon the concentration of DMI. Furthermore, DMI was found to increase the intracellular calcium concentration and mRNA expression of caspase-3 in renal tubular and glioma cells $(14,15)$. An increase in intracellular calcium also induced apoptosis in skin squamous carcinoma cells (30). We also found that the growth inhibition of $\mathrm{Ca} 3 / 7$ cells by DMI seems to be dependent on the extracellular calcium concentration (data not shown). In conclusion, the mRNA level of caspases, translocation of AIF to the nucleus and induction of apoptosis as well as the mRNA level of Bcl-xL from the anti-apoptotic Bcl-2 gene family were increased by DMI in our study. Gascoyne et al demonstrated that the GR binding site present in the promoter region of Bcl-xL was observed in dexamethasone-treated fibrosarcoma by transcriptionally activating GR which then regulated the expression of Bcl-xL (31). Spiegelman et al previously reported that $\mathrm{Ca} 3 / 7$ cells were resistant to glucocorticoids without alteration of GR expression and gene structure when compared to 3PC and MT1/2 cells (24). These findings suggest that Bcl-xL may play a pivotal role in mediating the anti-apoptotic effects of glucocorticoid in Ca3/7 cells. Huang et al reported that an increase in mRNA expression of Bcl-2, inhibition of caspases and apoptosis were induced by a low concentration of DMI (19). It is possible that the Bcl-2 family may be a key target in DMI-induced cell viability. Furthermore, the expression balance of the Bcl-2 family may suggest that DMI causes the induction of apoptosis at different concentrations in different cell lines. This idea is conceivable since several studies reported findings both for and against the association of antidepressant use with cancer risk in clinical studies (32-35).

Cell cycle progression is well controlled by the activation and inactivation of cyclin-dependent kinase (CDK) (9). G1 to $\mathrm{S}$ phase transition is one of the most important steps in the cell cycle which brings cells to DNA replication followed by G2 phase and subsequent mitosis. Many types of cancer cells demonstrate $\mathrm{G} 1$ checkpoint abrogation, a common phenomenon in carcinogenesis. p21 and p27 have been reported to regulate cell cycle progression by direct inhibition of CDKs (36) resulting in G2 arrest $(37,38)$. We found that growth inhibition induced by DMI was associated with accumulation of the cell cycle in the $\mathrm{G} 1$ and $\mathrm{G} 2 / \mathrm{M}$ phases. Cultivation with $20 \mu \mathrm{M}$ DMI for $24 \mathrm{~h}$ increased the proportion of cells in both the G1 and G2 phases, with a marked increase in mRNA expression of the CDK inhibitors p21 and p27. As reported by Arimachi and Morita, DMI induced cell cycle arrest in the G2/M phase in colon cancer cells (13). An increase in the expression of p21 was found to be associated with arrest in the $\mathrm{G} 2 / \mathrm{M}$ phase $(39,40)$. DMI seemed to cause arrest in the $\mathrm{G} 2 / \mathrm{M}$ phase at higher doses. However, the present study as well as previous studies suggest that DMI may have a different effect on the induction of apoptosis and the arrest of cell cycle progression at different concentrations. Therefore, the effects of different doses of $\mathrm{DMI}$ on the expression of the anti-apoptotic gene Bcl-xL and cell cycle progression-related genes CDKs and $\mathrm{p} 53$ require further study.

In conclusion, we showed that DMI inhibits cell viability by the induction of apoptosis and the arrest of cell cycle progression in mouse skin squamous cell carcinoma cells. We suggest that the mitochondrial pathway may be associated with the induction of apoptosis in Ca3/7 skin cancer cells and that $\mathrm{Bcl}-\mathrm{xL}$ may play a pivotal role in mediating the antiapoptotic effects. We also suggest that the growth inhibition induced by DMI may be associated with cell cycle arrest at the G1 and G2/M points and with increased expression of p21 and $\mathrm{p} 27$. Apoptosis has been recently identified as a useful target in anticancer therapies. Caspase-mediated apoptosis is a major focus in the field of cancer growth inhibition, as activation of the proteolytic caspase cascade is a critical component in the execution of programmed cell death. It is clear that a better understanding of the mechanism of DMIinduced apoptosis requires further investigation.

\section{Acknowledgements}

This study was supported by the National Cancer Institute Grant RO1 CA 0796065-09 (T.J.S.) and the Cancer Center Grant P30 CA 54174-16S1.

\section{References}

1. Chubak J, Buist DS, Boudreau DM, Rossing MA, Lumley T and Weiss NS: Breast cancer recurrence risk in relation to antidepressant use after diagnosis. Breast Cancer Res Treat 112: 123-132, 2008.

2. Wernli KJ, Hampton JM, Trentham-Dietz A and Newcomb PA: Antidepressant medication use and breast cancer risk. Pharmacoepidemiol Drug Saf 18: 284-290, 2009.

3. Tamim H, Boivin JF, Hanley J, Stang M and Collet JP: Risk of breast cancer in association with exposure to two different groups of tricyclic antidepressants. Pharmacoepidemiol Drug Saf 15: 689-697, 2006.

4. Fulton-Kehoe D, Rossing MA, Rutter C, Mandelson MT and Weiss NS: Use of antidepressant medications in relation to the incidence of breast cancer. Br J Cancer 94: 1071-1078, 2006.

5. Dalton SO, Poulsen AH, Norgaard M, McLaughlin JK, Johansen C and Friis S: Tricyclic antidepressants and nonHodgkin lymphoma. Epidemiology 19: 546-549, 2008.

6. Tamim HM, Mahmud S, Hanley JA, Boivin JF, Stang MR and Collet JP: Antidepressants and risk of prostate cancer: a nested case-control study. Prostate Cancer Prostatic Dis 11: 53-60, 2008.

7. Toh S, Rodriguez LA and Hernandez-Diaz S: Use of antidepressants and risk of lung cancer. Cancer Causes Control 18: 1055-1064, 2007.

8. Coogan PF: Review of the epidemiological literature on antidepressant use and breast cancer risk. Expert Rev Neurother 6: 1363-1374, 2006

9. Xu W, Tamim H, Shapiro S, Stang MR and Collet JP: Use of antidepressants and risk of colorectal cancer: a nested casecontrol study. Lancet Oncol 7: 301-308, 2006.

10. Gil-Ad I, Zolokov A, Lomnitski L, et al: Evaluation of the potential anti-cancer activity of the antidepressant sertraline in human colon cancer cell lines and in colorectal cancerxenografted mice. Int J Oncol 33: 277-286, 2008.

11. Peer D, Dekel Y, Melikhov D and Margalit R: Fluoxetine inhibits multidrug resistance extrusion pumps and enhances responses to chemotherapy in syngeneic and in human xenograft mouse tumor models. Cancer Res 64: 7562-7569, 2004.

12. Levkovitz Y, Gil-Ad I, Zeldich E, Dayag M and Weizman A: Differential induction of apoptosis by antidepressants in glioma and neuroblastoma cell lines: evidence for p-c-Jun, cytochrome c, and caspase-3 involvement. J Mol Neurosci 27: 29-42, 2005. 
13. Arimochi $\mathrm{H}$ and Morita K: Characterization of cytotoxic actions of tricyclic antidepressants on human HT29 colon carcinoma cells. Eur J Pharmacol 541: 17-23, 2006.

14. Qi H, Chen HZ and Jin ZJ: Caspase 3 gene expression and $\left[\mathrm{Ca}^{2+}\right] \mathrm{i}$ homeostasis underlying desipramine-induced C6 glioma cell apoptosis. Acta Pharmacol Sin 23: 803-807, 2002 .

15. Ho CM, Kuo SY, Chen CH, Huang JK and Jan CR: Effect of desipramine on $\mathrm{Ca}^{2+}$ levels and growth in renal tubular cells. Cell Signal 17: 837-845, 2005.

16. Tutton PJ and Barkla DH: Effect of an inhibitor of noradrenaline uptake, desipramine, on cell proliferation in the intestinal crypt epithelium. Virchows Arch B Cell Pathol Incl Mol Pathol 57: 349-352, 1989.

17. Iishi H, Tatsuta M, Baba M and Taniguchi H: Enhancement by the tricyclic antidepressant, desipramine, of experimental carcinogenesis in rat colon induced by azoxymethane. Carcinogenesis 14: 1837-1840, 1993.

18. Albouz S, Hauw JJ, Berwald-Netter Y, Boutry JM, Bourdon R and Baumann N: Tricyclic antidepressants induce sphingomyelinase deficiency in fibroblast and neuroblastoma cell cultures. Biomedicine 35: 218-220, 1981.

19. Huang YY, Peng CH, Yang YP, et al: Desipramine activated Bcl-2 expression and inhibited lipopolysaccharide-induced apoptosis in hippocampus-derived adult neural stem cells. J Pharmacol Sci 104: 61-72, 2007.

20. Pariante CM, Makoff A, Lovestone S, et al: Antidepressants enhance glucocorticoid receptor function in vitro by modulating the membrane steroid transporters. Br J Pharmacol 134: 1335-1343, 2001.

21. Pepin MC, Govindan MV and Barden N: Increased glucocorticoid receptor gene promoter activity after antidepressant treatment. Mol Pharmacol 41: 1016-1022, 1992.

22. Funato H, Kobayashi A and Watanabe Y: Differential effects of antidepressants on dexamethasonee-induced nuclear translocation and expression of glucocorticoid receptor. Brain Res 1117: 125-134, 2006.

23. Okuyama-Tamura M, Mikuni M and Kojima I: Modulation of the human glucocorticoid receptor function by antidepressive compounds. Neurosci Lett 342: 206-210, 2003.

24. Spiegelman VS, Budunova IV, Carbajal S and Slaga TJ: Resistance of transformed mouse keratinocytes to growth inhibition by glucocorticoids. Mol Carcinog 20: 99-107, 1997.

25. Kinjo T, Kowalczyk P, Kowalczyk M, Walaszek Z, Nishimaki T, Slaga TJ and Hanausek M: Desipramine inhibits the growth of a mouse skin squamous cell carcinoma cell line and affects glucocorticoid receptor-mediated transcription. Mol Carcinog 48: 1123-1130, 2009.

26. Lu T, Huang CC, Lu YC, et al: Desipramine-induced Caindependent apoptosis in Mg63 human osteosarcoma cells: dependence on P38 mitogen-activated protein kinase-regulated activation of caspase 3. Clin Exp Pharmacol Physiol 36: 297-303, 2009

27. Chang HC, Huang CC, Huang CJ, et al: Desipramine-induced apoptosis in human PC3 prostate cancer cells: activation of JNK kinase and caspase- 3 pathways and a protective role of $\left[\mathrm{Ca}^{2+}\right] \mathrm{i}$ elevation. Toxicology 250: 9-14, 2008.
28. Arimochi $\mathrm{H}$ and Morita $\mathrm{K}$ : Desipramine induces apoptotic cell death through nonmitochondrial and mitochondrial pathways in different types of human colon carcinoma cells. Pharmacology 81: 164-172, 2008.

29. Haller I, Lirk P, Keller C, Wang GK, Gerner P and Klimaschewski L: Differential neurotoxicity of tricyclic antidepressants and novel derivatives in vitro in a dorsal root ganglion cell culture model. Eur J Anaesthesiol 24: 702-708, 2007.

30. Hail N Jr and Lotan R: Apoptosis induction by the natural product cancer chemopreventive agent deguelin is mediated through the inhibition of mitochondrial bioenergetics. Apoptosis 9: 437-447, 2004

31. Gascoyne DM, Kypta RM and Vivanco MM: Glucocorticoids inhibit apoptosis during fibrosarcoma development by transcriptionally activating Bcl-xL. J Biol Chem 278: 18022-18029, 2003.

32. Sharpe CR, Collet JP, Belzile E, Hanley JA and Boivin JF: The effects of tricyclic antidepressants on breast cancer risk. Br J Cancer 86: 92-97, 2002.

33. Cotterchio M, Kreiger N, Darlington G and Steingart A: Antidepressant medication use and breast cancer risk. Am J Epidemiol 151: 951-957, 2000.

34. Dublin S, Rossing MA, Heckbert SR, Goff BA and Weiss NS: Risk of epithelial ovarian cancer in relation to use of antidepressants, benzodiazepines, and other centrally acting medications. Cancer Causes Control 13: 35-45, 2002.

35. Wang PS, Walker AM, Tsuang MT, Orav EJ, Levin R and Avorn J: Antidepressant use and the risk of breast cancer: a nonassociation. J Clin Epidemiol 54: 728-734, 2001.

36. Lee YM and Sicinski P: Targeting cyclins and cyclin-dependent kinases in cancer: lessons from mice, hopes for therapeutic applications in humans. Cell Cycle 5: 2110-2114, 2006.

37. Charrier-Savournin FB, Chateau MT, Gire V, Sedivy J, Piette J and Dulic V: p21-mediated nuclear retention of cyclin B1-Cdk1 in response to genotoxic stress. Mol Biol Cell 15: 3965-3976, 2004.

38. Nigam N, Prasad S, George J and Shukla Y: Lupeol induces p53 and cyclin-B-mediated $\mathrm{G} 2 / \mathrm{M}$ arrest and targets apoptosis through activation of caspase in mouse skin. Biochem Biophys Res Commun 381: 253-258, 2009.

39. Levesque AA, Fanous AA, Poh A and Eastman A: Defective p53 signaling in p53 wild-type tumors attenuates p21waf1 induction and cyclin $\mathrm{B}$ repression rendering them sensitive to Chk1 inhibitors that abrogate DNA damage-induced S and G2 arrest. Mol Cancer Ther 7: 252-262, 2008.

40. Choi EJ and Kim GH: Apigenin causes G(2)/M arrest associated with the modulation of p21(Cip1) and Cdc2 and activates p53dependent apoptosis pathway in human breast cancer SK-BR-3 cells. J Nutr Biochem 20: 285-290, 2009. 